\title{
Determinants of modern health care use by families after a childhood burn in Ghana
}

\author{
Samuel N Forjuoh, Bernard Guyer, Donna M Strobino
}

\begin{abstract}
Objectives - This study examined determinants of modern health care use by families after their child aged $0-5$ years sustained a burn injury in the Ashanti Region of Ghana.
\end{abstract}

Methods - A community based survey of children aged $0-5$ years was conducted in 50 enumeration areas in the region. Mothers of all children with scars as evidence of a burn were selected for a follow up interview using a standard questionnaire two to three months later. Determinants of health care use were investigated through a multivariate logistic regression using interview responses from mothers of 617 children for whom report on some treatment was given.

Results-Overall, $48 \%$ of the burned children were taken to a modern health facility for treatment. Of those taken to a modern health facility, $68 \%$ were sent within 24 hours of the burn event. Factors with large adjusted odds ratios for modern health care use included wound infection, burns covering $6 \%$ or more of the body surface, and third degree burns. Compared with scalds, children with contact and flame burns were less likely to be taken to a health facility, as were burns to rural children, and those given first aid treatment at home.

Conclusions-It is concluded that families, particularly rural residents, should be educated about appropriate health care seeking practices after a burn. (Injury Prevention 1995; 1: 31-34)

Keywords: burns, determination of health care needs, Ghana, health care seeking behavior.

In developing countries many options for health care seeking exist, ranging from home based treatment to use of sophisticated modern tertiary centers. ${ }^{1-4}$ Between these two extremes of treatment options lie other options such as spiritualists, herbalists, and other traditional healers. ${ }^{5}$ Reasons for choosing one option or another reported in previous studies include distance from the home, accessibility to the facility, belief in and acceptability of services, social status, and household income. ${ }^{6-12}$

For many disease conditions, the determination of health care needs has also been based on the perception of the disease. ${ }^{35}$ In Ghana, for example, mental disorders are believed to be spiritual and are rarely treated at modern health facilities. Rather, individuals with mental disorders are sent to alternative providers such as spiritualists and fetish priests (SN Forjuoh, personal observations). For reasons including easy access, low costs, and uncomplicated procedures, drug peddlers are mainly used for minor ailments. To date, no study in Ghana has examined peoples' behaviors and practices regarding health care seeking for injuries specifically. This report describes the results of a study of determinants of modern health care use by families in. Ghana after their child, aged 0-5 years, had a burn injury. This information will be invaluable to the planning and implementation of appropriate preventive programs and policy changes regarding the issue of burns and access to care in Ghana.

\section{Methods \\ STUDY AREA}

Ashanti Region, the study area, is one of 10 regions in the Republic of Ghana. It is the most populous region, with an estimated population of 2.3 million, and is divided into 18 administrative districts. ${ }^{13}$ Typical of most developing countries, the population is young: $47 \%$ are below 15 years of age. The economy of the region is based on agriculture, although gold mining is also of significance. Cocoa farming for export is the single largest activity; however, subsistence farming is also practiced widely. Approximately $35-40 \%$ of the people in the region live in urban areas. The region is ethnically homogenous with Akans, but people of other ethnic origins are found throughout.

The health system of the region, like the rest of the country, is made up of three tiers. The district hospitals (level C) form the highest level and are managed by district health management teams. Level $B$ is comprised of health centers and posts, which are staffed by at least one medical assistant or medical officer, a midwife, community health nurses, and health inspecting assistants. Level $A$ is made up of primary health care centers managed by village health workers, who have had some formal health training and provide health care at the community level. There is a teaching (referral) hospital in Kumasi, the regional capital.

\section{STUDY SUBJECTS}

Data for this study were derived from a childhood burn survey in the Ashanti Region. The broad objectives of the survey were to deter-

Street, Room

NE-560/MUH, Pittsburgh, PA 15213, USA. 
mine the prevalence and risk factors for burns and their related impairments and disabilities, study the epidemiological characteristics, estimate age specific incidence rates, and other factors concerning burns to children aged $0-5$, such as intentional burns and health care use in order to assist in future preventive efforts. Details of the sampling methods, response rates, and representativeness of the study population have been published elsewhere. ${ }^{14}$ Briefly, a community based survey of children aged 0-5 years was conducted in 50 sites (enumeration areas) in the region. Mothers of all children $(n=955)$ with scars as evidence of a burn were selected for a follow up interview two to three months later using a standard questionnaire. We successfully interviewed mothers of $630(66 \%)$ children. Mothers of the remaining children could not be interviewed due to inaccessibility to four of the $\mathbf{5 0}$ sites the second time around on account of bad weather, relocation of the family, failure to locate the dwelling, and absence after two attempts. The interviewed subjects were significantly older. The study protocol was approved by the Human Subjects Committee of the Johns Hopkins University and the Ministry of Health of Ghana.

Responses from $617(98 \%)$ mothers of the burned children who reported some treatment were analyzed for this study. The standard interview questionnaire elicited information on the child, events surrounding the burn and the phase after the burn, and socioenvironmental factors (see table 1). Wound infection was defined as any burn wound from which emanated pus, a greenish material, or which was described by a health worker as infected.

\section{STATISTICAL ANALYSIS}

We defined our dependent variable, use of modern health care, as either taking the burned child to a modern health care facility after the burn injury or not. To evaluate determinants of modern health care use, each of the independent variables of interest listed in table 1 was compared with the dependent variable using the $\chi^{2}$ test $(\alpha=0.05)$.

Table 1 Variables used in analysis of determinants of modern health care use by families after a childhood burn in Ashanti Region, Ghana

\section{Host variables}

Age (at time of burn)

Ethnicity

Residence

History of previous injury

Pre-existing impairment

Burn characteristics

Cause of burn

Size of burn (\% BSA)

Depth of burn

Intent of burn

Treatment and access factors

Administration of first aid treatmen

Contact with modern health facility

Distance to facility

Time of day of burn

Burn wound infection

Burn related physical impairmen

Burn related physical disability

Travel time to facility

Mode of getting to nearest facility

Level of facility

Socioenvironmental factors

Mother's education

Mother's occupation

Mother's income

Family size

Ownership of first aid kit

Presence of an adult at time of burn

Sibling burn history

BSA $=$ body surface area
Crude odds ratios (ORs) and $95 \%$ confidence intervals were computed for each independent variable in relation to health care use. Adjusted ORs for determinants of modern health care use were estimated using logistic regression modeling through: identification of independent variables significant at the $p=$ $0 \cdot 10$ level in the preliminary analysis; fitting multivariate models using the $0 \cdot 20$ level as a criterion for inclusion of variables in the model; and recommendation of a final model based on evaluation of interactions, likelihood ratio testing among models, and goodness of fit assessment.

\section{Results}

\section{VISIT TO A MODERN HEALTH FACILITY}

Of the 617 children for whom a report on some treatment was given, $302(48 \%)$ were taken to a modern health facility for burn treatment by their families; 315 children were not. Of those who were taken to a modern health facility, $68 \%$ were sent within 24 hours of the event, $26 \%$ after one day but within one week, $3 \%$ between one week and one month, and 3\% after one month. The major reasons for a delay in seeking modern care were reported as lack of knowledge about the seriousness of the burn injury $(33 \%)$, financial reasons $(32 \%)$, and time constraints $(12 \%)$.

\section{PUTATIVE DETERMINANTS OF MODERN}

HEALTH CARE USE

Table 2 shows the bivariate relationships of selected independent variables with use of a modern health facility. Visit to a health facility was strongly associated with residence and whether a home based first aid had been given. Urban residents were more likely to take their burned child to a modern health facility than semiurban or rural residents. Children who were given first aid at home were less likely to be taken to a modern health facility than children who were not. Other significant determinants of health care use in the bivariate analyses were body surface area burned; cause of the burn; depth of the burn; distance to the nearest modern health facility; ownership of a color television or a house; presence of an adult at the time of the burn; time of day of the burn; tribe (ethnicity); sibling burn history; and wound infection. Health care seeking was independent of the travel time to the nearest modern health facility.

\section{ADJUSTED ODDS RATIOS FOR} DETERMINANTS OF MODERN HEALTH CARE USE

After multivariate adjustment, wound infection became more strongly predictive of modern health care use, with its OR increasing from an unadjusted value of 3.77 to an adjusted value of $5 \cdot 10$ (table 3 ). The OR for body surface area of $6 \%$ or more, the factor with the strongest unadjusted $\mathrm{OR}$ (unadjusted $\mathrm{OR}=$ 6.35 ), was reduced in the multivariate analysis (adjusted $\mathrm{OR}=4.35$ ), although its relationship 
Table 2 Modern health care use for childhood burns by selected characteristics, Ashanti Region, Ghana

\begin{tabular}{|c|c|c|c|}
\hline Variable & $\begin{array}{l}\text { Total No } \\
\text { with burns } \\
(n=617)\end{array}$ & $\begin{array}{l}\text { No }(\%) \text { of } \\
\text { total seeking } \\
\text { health care } \\
(n=302)\end{array}$ & Test \\
\hline $\begin{array}{l}\text { Administration of } \\
\text { No } \\
\text { Yes } \\
\text { Unknown }\end{array}$ & $\begin{array}{c}\text { first aid } \\
139 \\
467 \\
11\end{array}$ & $\begin{array}{r}97(69 \cdot 8) \\
201(43.0) \\
4(36 \cdot 4)\end{array}$ & $\begin{array}{l}\chi^{2}=30.65 \\
\mathbf{p}<0.001\end{array}$ \\
\hline $\begin{array}{l}\text { Area of residence } \\
\text { Urban } \\
\text { Semiurban } \\
\text { Rural }\end{array}$ & $\begin{array}{l}175 \\
171 \\
271\end{array}$ & $\begin{array}{r}114(65 \cdot 1) \\
85(49 \cdot 7) \\
103(38 \cdot 0)\end{array}$ & $\begin{array}{l}\chi^{2}=31.39 \\
\mathbf{p}<0.001\end{array}$ \\
\hline $\begin{array}{c}\text { Body surface area } \\
1-2 \% \\
3-5 \% \\
>6 \%\end{array}$ & $\begin{array}{c}\text { burned } \\
520 \\
67 \\
30\end{array}$ & $\begin{array}{r}229(44 \cdot 0) \\
48(71 \cdot 6) \\
25(83 \cdot 3)\end{array}$ & $\begin{array}{l}\chi^{2}=33.65 \\
\mathrm{p}<0.001\end{array}$ \\
\hline $\begin{array}{l}\text { Cause of burn } \\
\text { Scalds } \\
\text { Contact } \\
\text { Flame } \\
\text { Other` } \\
\text { Unknown }\end{array}$ & $\begin{array}{r}277 \\
208 \\
119 \\
7 \\
6\end{array}$ & $\begin{array}{r}171(61 \cdot 7) \\
80(38 \cdot 5) \\
49(41 \cdot 2) \\
2(28 \cdot 6) \\
0\end{array}$ & $\begin{array}{l}\chi^{2}=30.01 \\
\mathrm{p}<0.001\end{array}$ \\
\hline $\begin{array}{l}\text { Depth of burn } \\
\text { 1st degree } \\
\text { 2nd degree } \\
\text { 3rd degree } \\
\text { Unknown` }\end{array}$ & $\begin{array}{r}69 \\
413 \\
129 \\
6\end{array}$ & $\begin{array}{r}29(42 \cdot 0) \\
191(46 \cdot 2) \\
79(61 \cdot 2) \\
3(50 \cdot 0)\end{array}$ & $\begin{array}{l}\chi^{2}=10.33 \\
\mathbf{p}<0.001\end{array}$ \\
\hline $\begin{array}{l}\text { Distance to neares } \\
0-3 \text { miles } \\
>3 \text { miles }\end{array}$ & $\begin{array}{l}t \text { facility } \\
476 \\
141\end{array}$ & $\begin{array}{r}256(53 \cdot 8) \\
46(32 \cdot 6)\end{array}$ & $\begin{array}{l}\chi^{2}=19.49 \\
p<0.001\end{array}$ \\
\hline $\begin{array}{l}\text { TV/house ownerst } \\
\text { No } \\
\text { Yes }\end{array}$ & $\begin{array}{l}\text { hip } \\
274 \\
273\end{array}$ & $\begin{array}{l}157(45 \cdot 6) \\
145(53 \cdot 1)\end{array}$ & $\begin{array}{l}\chi^{2}=3.40 \\
\mathbf{p}<0.1\end{array}$ \\
\hline $\begin{array}{l}\text { Adult presence at } t \\
\text { No } \\
\text { Yes } \\
\text { Unknown }\end{array}$ & $\begin{array}{l}\text { time of burn } \\
171 \\
427 \\
19\end{array}$ & $\begin{array}{r}74(43 \cdot 3) \\
225(52 \cdot 7) \\
3(15 \cdot 8)\end{array}$ & $\begin{array}{l}\chi^{2}=4.33 \\
\mathbf{p}<0.05\end{array}$ \\
\hline $\begin{array}{l}\text { Time of day of eve } \\
\text { Morning } \\
\text { Afternoon } \\
\text { Evening } \\
\text { Night } \\
\text { Unknown }\end{array}$ & $\begin{array}{r}\text { nt } \\
214 \\
166 \\
196 \\
22 \\
19\end{array}$ & $\begin{array}{r}111(51 \cdot 9) \\
69(41 \cdot 6) \\
107(54 \cdot 6) \\
8(36 \cdot 4) \\
7(36 \cdot 8)\end{array}$ & $\begin{array}{l}\chi^{2}=8.21 \\
\mathrm{p}<0.05\end{array}$ \\
\hline $\begin{array}{l}\text { Travel time to nea } \\
0-1 \text { hour } \\
<1 \text { hour }\end{array}$ & $\begin{array}{l}\text { rest facility } \\
592 \\
25\end{array}$ & $\begin{array}{r}291(49 \cdot 2) \\
11(44 \cdot 0)\end{array}$ & $\begin{array}{l}\chi^{2}=0.26 \\
\mathbf{p}<0.6\end{array}$ \\
\hline $\begin{array}{l}\text { Tribe (ethnicity) } \\
\text { Non-Akan } \\
\text { Akan }\end{array}$ & $\begin{array}{r}95 \\
522\end{array}$ & $\begin{array}{r}57(60.0) \\
245(46.9)\end{array}$ & $\begin{array}{l}\chi^{2}=5.49 \\
\mathbf{p}<0.05\end{array}$ \\
\hline $\begin{array}{l}\text { Sibling burn histo } \\
\text { No } \\
\text { Yes } \\
\text { Unknown }\end{array}$ & $\begin{array}{r}\text { ry } \\
487 \\
119 \\
11\end{array}$ & $\begin{array}{r}250(51 \cdot 3) \\
42(35 \cdot 3) \\
10(90 \cdot 9)\end{array}$ & $\begin{array}{l}\chi^{2}=9.86 \\
\mathbf{p}<0.001\end{array}$ \\
\hline $\begin{array}{l}\text { Wound infection } \\
\text { No } \\
\text { Yes }\end{array}$ & $\begin{array}{r}582 \\
35\end{array}$ & $\begin{array}{r}275(47 \cdot 3) \\
27(77 \cdot 1)\end{array}$ & $\begin{array}{l}\chi^{2}=11.81 \\
\mathrm{p}<0.001\end{array}$ \\
\hline
\end{tabular}

${ }^{\star}$ Not used in test.

with use of modern health care remained strong. The depth of the burn remained a strong predictor of modern care use in the logistic regression.

Compared with scalds, childhood burns through contact with a hot object $(O R=0.48)$ and through flame $(O R=0.58)$ were less likely to be taken to a modern facility. So were burns for which first aid treatment was given $(O R=0.31)$, and burns to children residing in rural and semiurban areas. Surprisingly, families with a history of a previous childhood burn were also less likely to take their burned child to a health facility $(O R=0.59)$, probably for financial reasons. In addition, families were less likely to take their child to a health facility more than 3 miles $(4.8 \mathrm{~km})$ away from their home $(O R=0.52)$.

Although significant in the bivariate analysis, tribe (ethnicity), time of day of the burn, and travel time to the nearest health facility were not predictive of modern health care seeking after multivariate adjustment. As a result, they were not included in the regression models reported in table 3.

\section{Discussion}

We investigated determinants of modern health care use for childhood burns by Ghanaian families in this study. Forty eight per cent of burned children were taken to a modern health facility for treatment in this study, a figure that is high for a developing country. In a community based study in Karachi, only $31.6 \%$ of burned patients of all ages reported seeking qualified medical care at the time of a burn. ${ }^{15}$ In a cross sectional survey of 2000 households in rural Ghana in 1972, Belcher et al found that only $27 \cdot 1 \%$ of the households reported using modern health facilities in general. ${ }^{2}$ In Nigeria, only $39.6 \%$ of 260 mothers reported seeking modern treatment for all conditions. ${ }^{1}$ The relatively high rate of modern health care seeking in this study may be partly related to the surgical nature of the condition. Another explanation could be the positive impact of the primary health care strategy of the Ministry of Health, which has been encouraging people to seek modern help for all ailments. However, missing $34 \%$ of children, who were significantly younger, in the follow up survey could have biased this estimate, as well as any inferences based on age distribution.

Of the significant determinants of modern health care seeking after a burn injury, the majority were related to its severity-namely, wound infection, extensive burns, and deep (third degree) burns. This finding was not surprising and may be related to the people's perception of burn injuries. In another study in Ghana, the perceived cause of a disease was found to have a major effect on the choice of service. $^{3}$

Only one significant predictor of use, ownership of a television or a house, was related to socioeconomic status, indicating that poor people have less access to health care, even for an injury. However, these possessions selected as a proxy measure for socioeconomic status may not be stable across geographic areas because possessions may have different meanings in different residential settings. For example, the value of a village house does not compare with that in the city. In two separate studies, Belcher et al and Gesler described users of health care facilities to include people of higher socioeconomic status, educated women, and younger people. ${ }^{12}$ None the less, conflicting findings were reported in a study of 1097 participants aged 15 years and above in Zambia. ${ }^{16}$ In this study, age and literacy level were found to have no effect on the people's health seeking behaviour in Kabinga. Moreover in the present study, although ownership of possessions was related to health care seeking, mother's education was not an important factor. We could not find an explanation for this finding.

Our results suggest that there is the need to augment education and communication about modern health care use in Ghana, given the factors that were found to hinder health care 
Table 3 Crude (unadjusted) and adjusted ORs and 95\% confidence intervals (95\% CI) of determinants of modern health care use for childhood burns, Ashanti Region, Ghana

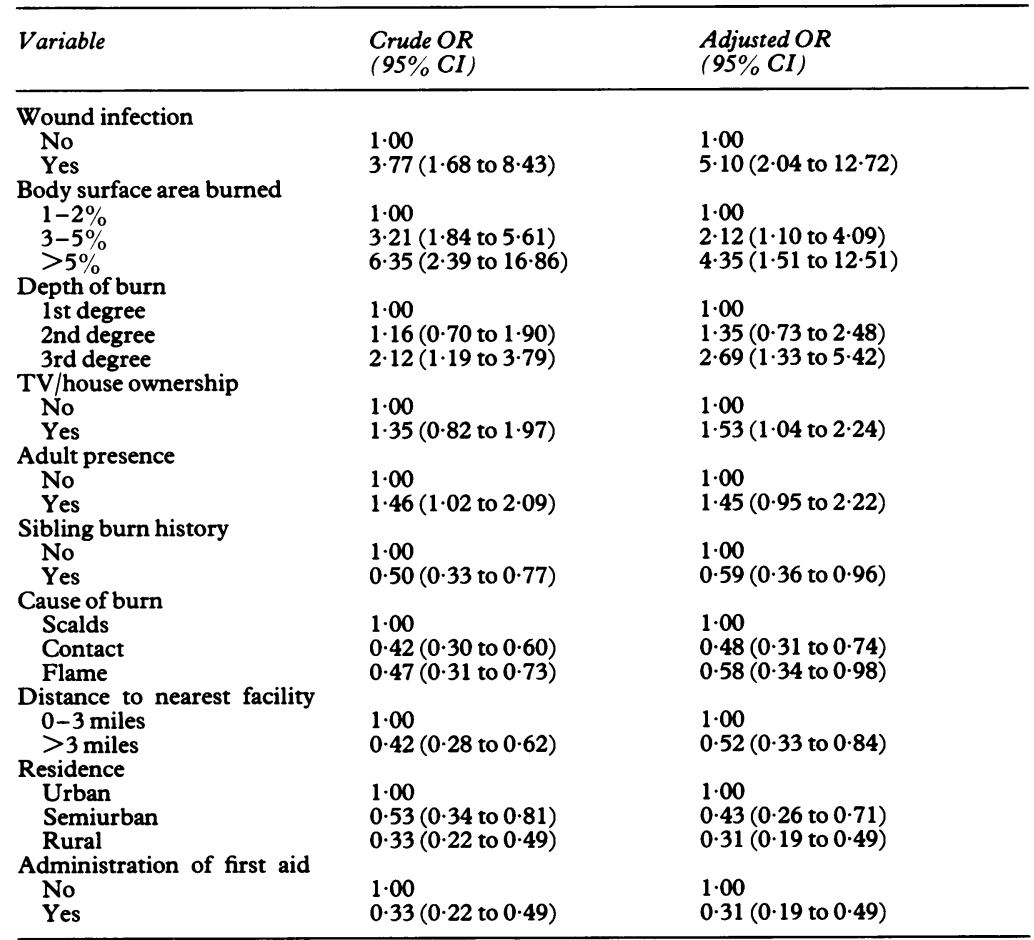

seeking. These factors included administration of first aid treatment, non-urban residence, distance to the nearest facility of greater than 3 miles, burns other than scalds, and history of a childhood burn in the family. The most common first aid treatment in this region is the use of traditional preparations-preparations which could lead to wound infection and further complications. ${ }^{14}$ Therefore, the immediate application of cool water to burns should be incorporated and emphasized in any educational messages.

With the primary health care concept deeply rooted in the health set-up of Ghana, there is a health station within close proximity of most settlements. In spite of this, some families failed to seek care if the nearest modern health facility was more than 3 miles away from their home, although many people in the Ashanti Region may walk for over 10 miles in order to reach their farms. This finding could mean that cost is a major issue, overriding the effects of distance and travel time and acting as a disincentive, and therefore health policy makers in Ghana should examine the relative high cost of health care. Not surprisingly, travel time, which is directly related to distance to health facilities, was not an important determinant of care seeking. Physical proximity and distance decay have been established as important factors in the use of health care resources in other studies in developing countries. ${ }^{17} 18$

In conclusion, the findings of this study call for the need to encourage more Ghanaian families, particularly rural residents, to seek modern health care for all kinds of burns, even after administering first aid treatment at home. While the authors support the establishment of specialized burn treatment centers in the large health facilities, and the need for rehabilitation and care of old burns, including reconstructive surgery, the training of local health personnel to better manage burns is also strongly recommended. By training village health workers to administer appropriate first aid to burns, people will have more confidence in seeking modern care from them, without having to necessarily travel to larger centers and incur higher costs.

This research formed part of Dr Forjuoh's doctoral thesis at the Johns Hopkins University. Dr Forjuoh was sponsored by fellowships from the World Health Organization, the Johns Hopkins University, the Dalhousie (Canada)/Kumasi (Ghana) Education and Development Project, and the Maternal and Child Health Block Training Grant.

The authors wish to acknowledge the help from the Department of Community Health at the University of Science and Technology School of Medical Sciences, Kumasi, Ghana. We lso thank Professors Susan Baker, Penelope Keyl, Marie Diener-West, and Gordon Smith for their assistance.

Funds for this research were provided by grants from the Rockefeller Foundation African Dissertation Internship Award, Now York, USA (RF 91037) and the International De ment Research Center, Ottawa, Canada (92-0217).

This report was presented, in part, at the 122nd annual meeting of the American Public Health Association in Washington, DC, October-November, 1994.

Gesler WM. Morbidity measurement in household survey in developing areas. Soc Sci Med 1976; 13: 223-6.

2 Belcher DW, Wurapa FK, Newman AK, Lourie IM. A household morbidity survey in rural Africa. Int $f$ Epidemiol 1976; 5: 113-20.

3 Fosu GB. Access to health care in urban areas of developing societies. F Health Soc Behav 1989; 30: 398-411.

4 Hunte PA, Sultana F. Health-seeking behavior and the meaning of medications in Balochistan, Pakistan. Soc Sci Med 1992; 34: 1385-97.

5 Twumasi PA Medical systems in Ghana. Tema, Ghana: Ghana Publishing Corporation, 1975.

6 King $M$. Medical care in developing countries. London: Oxford University Press, 1966.

7 Kleinman A. Patients and healers in the context of culture. Berkeley: University of California Press, 1980.

8 Finkler K. A comparative study of health seekers: or, why do some people go to doctors rather than to spiritual healers? Med anthropol 1981; Fall: 383-424.

9 Feldman S. The use of private health care providers in rura Bangladesh: a response to Claquin. Soc Sci Med 1983; 17 1887-96.

10 Chernichovsky K, Astra Meesook O. Utilization of health services in Indonesia. Soc Sci Med 1986; 23: 611-20.

11 Ogoh Alubo S. Power and privileges in medical care: an analysis of medical services in post-colonial Nigeria. Soc Sci Med 1987; 24: 453-62.

12 Bailey W, Phillips DR. Spatial patterns of use of health services in the Kingston Metropolitan Area, Jamaica. Soc Sci Med 1990; 30: 1-12.

13 Ministry of Finance and Economic Planning. 1984 Popula tion census of Ghana. Demographic and economic charaction census of Ghana. Demographic and economic charac-
teristics, Ashanti Region. Accra, Ghana: Statistical Serteristics, $A$

14 Forjuoh SN, Guyer B, Smith GS. Childhood burns in Ghana: epidemiological characteristics and home-based treatment. Burns 1995 (in press)

15 Durrani KM, ed. The epidemiology of burn injuries. 1st Ed. Karachi: Mirror Press, 1974

16 Kaona FA, Siziya S, Mushanaga M. The problems of a socia survey in epidemiology: and experience from a Zambia rural community. African fournal of Medicine and Medical Science 1990; 19: 219-24.

17 Shannon GW, Skinner JL, Bashshur RL. Time and distance: the journey for medical care. Int $\mathcal{f}$ Health Serv 1973; 3: 237-43.

18 Stock R. Distance and the utilization of health facilities in rural Nigeria. Soc Sci Med 1983; 17: 563-70. 